\title{
Campo estatal de administração de conflitos: múltiplas intensidades da justiça
}

\section{Jacqueline Sinhoretto}

\section{(2) OpenEdition \\ 1 Journals}

Edição electrónica

URL: http://journals.openedition.org/aa/930

DOI: 10.4000/aa.930

ISSN: 2357-738X

Editora

Programa de Pós-Graduação em Antropologia Social (UnB)

\section{Edição impressa}

Data de publição: 1 dezembro 2010

Paginação: 109-123

ISSN: 0102-4302

\section{Refêrencia eletrónica}

Jacqueline Sinhoretto, «Campo estatal de administração de conflitos: múltiplas intensidades da justiça», Anuário Antropológico [Online], v.35 n.2 | 2010, posto online no dia 02 novembro 2015, consultado o 28 abril 2021. URL: http://journals.openedition.org/aa/930 ; DOI: https://doi.org/ 10.4000/aa.930

\section{(c) (i) $९$}

Anuário Antropológico is licensed under a Creative Commons Atribuição-Uso Não-Comercial-Proibição de realização de Obras Derivadas 4.0 International. 


\title{
Campo estatal de administração de conflitos: múltiplas intensidades da justiça
}

\author{
Jacqueline Sinhoretto \\ Departamento de Sociologia/UFSCar
}

Este texto é um registro parcial da construção de um objeto de pesquisa e traz uma formulação interpretativa, ainda em estágio inicial, ${ }^{1}$ sobre as características e o funcionamento do campo estatal de administração de conflitos no Brasil, onde podem ser identificados ao menos quatro níveis de intensidade, com lógicas próprias, para a existência dos quais concorrem as dinâmicas das corporações do sistema de justiça, as disputas entre diferentes formas de saber e fazer, a mobilização de distintos rituais de administração de conflitos, com resultados e efeitos diversos.

\section{Como o objeto tem sido construído}

Duas vertentes teóricas são importantes para se localizarem as preocupações contemporâneas de uma antropologia política da administração de conflitos. De um lado, uma vertente antropológica que remonta aos estudos de Louis Dumont (1966) sobre as relações hierárquicas, e que se consolidou com a contribuição de Roberto DaMatta, segundo a qual a sociedade brasileira viveria um dilema entre práticas sociais hierárquicas - em que cada um tem o seu lugar, com direitos e deveres particulares - e uma representação das relações jurídicas como igualitárias incorporada ao direito constitucional de pretensão universalista. O dilema entre duas ordens de classificação produz atritos nas relações, os quais são frequentemente negociados em ritos de hierarquização, como o tornado célebre "você sabe com quem está falando?” (DaMatta, 1979).

Para Roberto Kant de Lima (1997, 2004), o dilema referido produz uma cultura jurídica peculiar, que atribui às instituições policiais e judiciais o papel de mediação entre lógicas jurídicas contraditórias, colocando as instituições e seus agentes em posição liminar e passível de acusação sistemática de erro e abuso. Esta cultura jurídica peculiar é ainda o que impulsiona as instituições formais a permanentemente administrarem conflitos por vias informais. A informalidade serve para evitar o tratamento legal igualitário a litigantes entendidos como desiguais, serve à adaptação das situações a conveniências pessoais e estatutárias dos agentes e pode até atender às expectativas das próprias partes, quando se satisfazem com as soluções que repõem a ordem hierárquica ou conseguem ver atendidas as suas pretensões. 
Essa antropologia da administração institucional de conflitos trabalha para derrubar a imagem de "inocência" da informalidade que uma vulgata da antropologia jurídica clássica se compraz em "descobrir" nas sociedades tradicionais. Nessa imagem, a informalidade seria o modo com que as "comunidades" (imaginadas como conjuntos coesos e homogêneos dos quais estariam ausentes os conflitos e as relações de poder) resolveriam seus próprios conflitos (como se eles fossem sempre originados por processos autônomos e estritamente locais e nunca fossem afetados por colonialismos e dominações), segundo métodos próprios que, sendo derivados de uma natureza humana boa e primitiva, estariam sempre orientados pelo consenso e pela equidade. ${ }^{2}$

A outra vertente importante para a construção de uma antropologia política da administração estatal de conflitos foi influenciada pelo "efeito Foucault" (Miller et al., 1991) e o entendimento de que as normas e as instituições judiciais são atravessadas por dispositivos de poder globalmente presentes, relacionados à disciplina ou à governamentalidade. A partir dos estudos influenciados por Foucault, implementam-se uma nova forma de estudar a política e uma possibilidade renovada de abordagem das instituições estatais, ligando sua lógica de funcionamento a formas de circulação de poder que estão, ao mesmo tempo, dentro e fora do Estado. Esses estudos foram perturbando a construção clássica de objetos como normas jurídicas, Estado, sociedade, punição, política e até direito. Mostraram que a técnica é politizada e incentivaram uma politização do campo jurídico estatal.

A convergência entre estas duas vertentes, damattiana e foucaultiana, tem possibilitado bons insights, como aquele compartilhado entre Roberto Kant de Lima, Michel Misse e Luís Roberto Cardoso de Oliveira, que questiona a possibilidade de pensar a sociedade brasileira como plenamente disciplinar (no sentido foucaultiano), uma vez que a coexistência das lógicas jurídicas igualitária e hierárquica torna muito difícil a introjeção subjetiva das regras pelos indivíduos, que nunca estão bem certos sobre qual sistema de regras será validado nas interações com outros indivíduos, principalmente se eles forem agentes estatais.

Outra construção favorecida por essa confluência é a do próprio conceito de campo estatal de administração de conflitos, que se tenta precisar aqui. ${ }^{4}$ A ideia de campo é emprestada de Bourdieu (2007), sendo este um espaço social estruturado por relações de força em que se desenvolvem lutas pelo direito de dizer o direito. Mas ela é transmutada pelas influências antropológica e foucaultiana a fim de compor um objeto que serve à compreensão da existência não apenas de corporações, saberes e instituições que competem nos limites de uma lógica relativamente autônoma, mas também de rituais de administração de conflitos que competem entre si e produzem resultados e efeitos díspares.

Em relação à leitura que, ao menos no Brasil, se faz do conceito de campo jurídico, o conceito de campo estatal de administração da justiça incorpora em sua análise o uso da informalidade e de técnicas não-judiciais de administração 
de conflito pelas instituições estatais. Considera que práticas informais, ilegais ou não referenciadas às leis escritas não são apenas defeitos de aplicação do direito ou falhas na implementação da lei cometidas por maus profissionais, mas são parte não-negligenciável de rituais de administração de conflitos que estão em disputa no interior do campo. Considera ainda que a divisão do trabalho no campo inclui, além das profissões e das posições classicamente vistas como jurídicas (jurista, juiz, promotor, advogado), outras posições que fracamente reproduzem o habitus jurídico, como aquelas subalternas das carreiras policiais, funcionários de cartórios, estagiários, conciliadores, mediadores, técnicos e peritos.

É claro que essas características não estão necessariamente excluídas do conceito de campo jurídico criado por Bourdieu, contudo, os estudos empíricos sobre a administração estatal de conflitos fora do contexto europeu e anglo-saxão chamam a atenção para a necessidade de ter categorias precisas para o entendimento da administração informal (e até ilegal) no interior das instituições formais. E o problema se torna ainda mais complexo - mesmo nos sistemas jurídicos europeus - na medida em que se universalizam as reformas judiciais que propõem a inclusão de ritos informais, orais, participativos, administrados por leigos ou profissionais emergentes. Há ainda a necessidade de lidar com as conclusões de um largo conjunto de pesquisas empíricas sobre a administração da justiça no Brasil que vem reiterando que o campo jurídico local não é capaz de filtrar, ressignificar e traduzir as hierarquias sociais em categorias e sentidos internos que o tornariam uma zona específica da cultura, defendida da influência do poder econômico e político. Ao contrário, o campo jurídico brasileiro não parece muito bem delimitado e defendido dessa influência. O conceito de campo, neste caso, é mais interessante em vista dos contrastes que evidencia em relação à realidade empírica francesa do que por sua aplicação acrítica.

A análise do campo estatal de administração de conflitos privilegia os papéis e as posições assumidos nos rituais pelos agentes estatais e seus representantes, e pelas partes em conflito, buscando compreender as relações estabelecidas entre eles, as equidades e as hierarquias produzidas, a produção e a circulação de verdades, a negociação dos significados de leis, normas, valores e direitos. Procura investigar os rituais de resolução no modo como encarnam valores e criam efeitos de produção, reprodução e modificação de relações de poder; e verificar, na prática cotidiana desses rituais, como eles são espaços de disputa de dois tipos simultâneos de monopólio estatal: o do uso legítimo da violência física e o de dizer o direito.

A ideia de um campo estatal é contraposta à noção de Estado como organização homogênea por se basear na constatação de que diferentes instituições estatais agem na administração de conflitos, e que cada uma delas o faz segundo suas lógicas e rituais, produzindo muitas vezes efeitos de equidade e hierarquização muito diferentes entre si. Além do mais, a antropologia política da administração 
de conflitos tem constatado que as instituições estatais, ao menos na experiência brasileira, não são cegas como deveria ser a Themis, deusa da justiça, mas, ao contrário, enxergam muito bem as clivagens sociais, raciais, de gênero, culturais e religiosas e reservam tratamento diferenciado para tipos de conflitos e para indivíduos conforme a posição que ocupam numa hierarquia de valores, pessoas, coisas e lugares. Sendo assim, um conceito de campo estatal permite ver muito além os conflitos e as disputas entre sistemas teórico-práticos concorrentes.

O conflito entre sistemas teórico-práticos anima a disputa entre agentes no cotidiano de cada instituição, mas esta disputa é também estruturada por uma hierarquia de tipos de conflitos, pessoas e lugares que faz com que o cotidiano num posto de trabalho na periferia da cidade seja completamente diferente daquele enfrentado no centro ou num bairro de classe alta, ou que uma delegacia e um tribunal especializados apliquem princípios de direito e justiça bastante diferenciados. Mesmo havendo uma legislação e um saber que definem o contraditório como princípio de organização do processo, a justiça da infância e juventude aplica princípios de controle social da infração diferentes dos aplicados a acusados de crimes comuns maiores de idade; delegacias e tribunais especializados em crimes econômicos mantêm métodos de investigação que pouco se parecem com o que se faz numa unidade ligada à violência no espaço doméstico.

Eficaz por permitir ver a pluralidade de rituais de administração de conflitos no seu interior, o conceito de campo informa ao mesmo tempo que esses rituais, essas instituições, esses agentes e postos de trabalhos estão todos referenciados uns aos outros porque há uma lógica hierárquica que atravessa e coordena todos e estabelece posições diferenciais para os tipos de conflitos, as pessoas, as coisas e os lugares.

Faz parte ainda da dinâmica do campo, pelo menos no momento contemporâneo, que os indivíduos alocados nas posições mais subalternas tentem estratégias para se deslocarem espacial ou simbolicamente para posições melhores: do lado dos agentes estatais, há uma competição profissional por postos de trabalho, acesso a redes de prestígio e por saberes técnicos; do lado dos usuários, há a busca por serviços alternativos e agentes que possam oferecer uma solução mais de acordo com suas expectativas, mas isto também depende do grau de conhecimento que os indivíduos possuem do campo, da extensão e do prestígio das redes em que circulam, das possibilidades financeiras de que dispõem, uma vez que há uma complexa malha de barreiras de acesso aos serviços estatais para ser enfrentada.

Existe no campo estatal uma disputa entre instituições em torno de formas de produção da verdade jurídica (Kant de Lima, 1989), autonomia em relação ao mundo da política convencional (Bonelli, 2002) e de representação de segmentos e lutas sociais (Silva, 2001). Essas disputas produzem hierarquias entre instituições, entre instâncias e grupos profissionais, entre formas de saber e práticas jurídicas. 
A política no interior do campo estatal de admistração de conflitos pode ainda se fazer por atores coletivos, como movimentos feminista, ambientalista, de consumidores, movimento negro, que por meio de suas lutas logram alterar legislações, obtêm a criação de serviços especializados e a de ritos judiciais específicos. E, logo em seguida, precisam se lançar nas microdisputas do cotidiano para fazer valerem na prática, em cada turno de cada posto de trabalho, as conquistas formais obtidas em nível global, para que disputem espaço com as soluções informais que podem ou não incorporar tais conquistas.

\section{Contribuição para a descrição do campo estatal de administração de conflitos}

Para tornar mais concreta a abstração teórica, um exercício de reflexão sobre o caso brasileiro leva à descrição de um campo com pelo menos quatro grandes lógicas de administração estatal de conflitos, ou quatro intensidades de interação, ou ainda quatro grandes níveis hierárquicos aos quais correspondem hierarquias de rituais, de pessoas e tipos de conflito. A tipologia aqui traçada é o resultado de uma etnografia desenvolvida entre 1999 e 2005 nas unidades do Centro de Integração da Cidadania, na cidade de São Paulo (Sinhoretto, 2007), acrescida de observações colhidas em pesquisas sobre o funcionamento da justiça criminal.

A escala de mais alta intensidade lida com os conflitos considerados os mais complexos, protagonizados por pessoas de alto prestígio social, com grande capital simbólico e financeiro, operando com grandes somas, que utilizam a plena potencialidade dos recursos de que dispõem para assegurar direitos e garantias e até para obter o reconhecimento de novos direitos e garantias. Um caso típico desse nível de altíssima intensidade é a trajetória do banqueiro Daniel Dantas pela justiça criminal, o qual foi beneficiário, na mesma semana, de dois habeas corpus expedidos pelo Supremo Tribunal Federal, a mais alta corte de justiça do país. Ou ainda a decisão expedida pelo mesmo STF em um processo também relacionado a crimes econômicos que declara ser inconstitucional o uso de algemas em prisioneiros que não apresentam resistência e não representam perigo social. Nesse nível de interação, as regras de investigação, produção de provas e processamento são questionadas e discutidas em rituais de ampla publicidade, e um policial ou promotor acusado de abuso de poder pode ter sua carreira profissional perturbada e/ou sua carreira política alavancada. ${ }^{5}$

As escalas de intensidade não são relativas apenas aos tipos de conflito, como quer a retórica de autojustificação do campo; ela relaciona a estes uma hierarquia de pessoas, sendo que pessoas de alto prestígio social conseguem transformar seus conflitos em grandes casos de justiça, em que todas as potencialidades do sistema de direito são exploradas e nenhuma forma de violação de seus direitos e garantias individuais passa desapercebida. É o caso da famosa atriz Luana Piovani, que obteve em 2009 a decretação de medidas protetivas 
assegurando-lhe direitos e prerrogativas sobre o ex-namorado Dado Dolabella, ator de menor prestígio, cuja prisão foi decretada, com amparo na Lei Maria da Penha (Lei 11.340/2006). Dias depois, ele foi solto, mas continuou constrangido a cumprir as restrições de direitos, sendo finalmente condenado em 2010. É claro que a lei pode ser igualmente aplicada a outros casos de violência contra a mulher, mas chama a atenção nessa escala de alta intensidade a rapidez e as facilidades que os indivíduos encontram para defender seus direitos na justiça e conseguir com que seus pleitos atravessem todo o sistema judiciário. ${ }^{6}$ Ninguém pode dizer nesses casos que a justiça seja lenta, arbitrária ${ }^{7}$ ou que esteja despreparada para lidar com a complexidade dos conflitos.

Outro caso que permite perceber que a gravidade do delito é medida pelo prestígio social do protagonista é o da atriz Daniela Perez. Era filha da famosa escritora de novelas Glória Perez e foi morta pelo ator com quem contracenava em seu primeiro papel importante na Rede Globo, em 1992. A repercussão de sua morte culminou com uma alteração da legislação penal que tornou mais grave o crime de homicídio qualificado (classificado doravante como crime hediondo), limitando garantias processuais do acusado e endurecendo as condições do cumprimento da pena. ${ }^{8}$

A segunda escala de intensidade corresponde aos rituais de administração de conflitos da justiça comum e é acessada por pessoas "mais comuns"; nela, a capacidade de mobilização dos recursos do direito é limitada pelas barreiras de acesso à justiça e pela excessiva burocratização dos procedimentos e das instâncias policiais e judiciais. De um lado, acusados têm recursos limitados de defesa conforme sua condição econômica, de classe, pertença racial, de gênero, religiosa, local de moradia, como atestam os dados do Conselho Nacional de Justiça que, em 2009, contabilizou 126 mil presos com pena vencida no sistema penitenciário, por não terem conseguido ter o seu caso apreciado a tempo pelas autoridades judiciais e carcerárias. De outro lado, vítimas de violação de direitos encontram dificuldades homólogas de acordo com sua posição na malha de hierarquias e o conhecimento das regras do jogo. São vítimas de violência que encontram dificuldades em ter o seu caso investigado, ou o tempo da tramitação arrasta-se até a prescrição, ou são litigantes da esfera cível que não conseguem executar a sentença judicial por desconhecerem os trâmites e os recursos, ou por não terem dinheiro suficiente para custear uma litigação longa e complexa. Nessa escala de intensidade, o sistema de justiça é acessível, mas as barreiras de acesso são consideráveis, os mecanismos seletivos são operantes e há vieses importantes na aplicação da justiça segundo o perfil social dos envolvidos.

A terceira escala, de baixa intensidade, é uma criação recente, introduzida como inovação para oferecer respostas aos "defeitos" do sistema judicial clássico e procura contornar as barreiras de acesso. São iniciativas de reforma que propõem simplificação processual ou informalização, que criam juizados de pequenas causas, 
ou juizados especiais. Os rituais de administração de conflitos apelam para a informalidade dos procedimentos, a oralidade, a celeridade e costumam se justificar socialmente pelo argumento da facilitação do acesso aos pequenos litigantes. Também, mais uma vez, fica clara a homologia entre intensidade no tratamento do conflito e posição social dos seus protagonistas.

As pequenas causas são as causas dos pequenos e justificam a criação de procedimentos, delegacias e juizados especiais, de pouquíssimo prestígio no campo, em nome de reservar o sistema judicial comum a outros conflitos e outros litigantes. É a retórica do desafogamento dos tribunais, que pressupõe que haja conflitos e litigantes que não sejam tão legítimos quanto os outros. Isto não quer dizer que os usuários dos juizados e dos serviços informalizados não possam ficar satisfeitos com o desfecho, mas sim que a qualidade jurídica das soluções pode ser bastante precarizada. ${ }^{9}$ Um exemplo foi a criação no Brasil da Lei 9.099/99, que instituiu Juizados Especiais que passaram a tratar os casos de violência doméstica; embora alguns estudos tenham apontado para a potencialidade dos juizados em criar novos arranjos políticos nas relações e aumentar o protagonismo das partes envolvidas na solução de seus problemas, eles foram massivamente criticados tanto pelo desprezo a garantias dos acusados como pela imposição de penas pífias e ineficazes que terminavam por revelar a desqualificação dos delitos de violência doméstica, tanto que a crítica feminista ao funcionamento dos juizados terminou por alavancar a aprovação de uma nova Lei (Maria da Penha), mais dura com os delitos cometidos em relações conjugais.

Mesmo nos países da Europa continental, com experiência mais profunda de consolidação de regras igualitárias, as reformas informalizantes têm sido analisadas através do prisma da institucionalização de sistema judiciais com duas velocidades, ${ }^{10}$ o que institucionalizaria desigualdades jurídicas. O que se pretende argumentar aqui é que, em geral, os campos estatais de administração de conflitos contemporâneos têm mais do que duas velocidades, especialmente aqueles onde a experiência da igualdade jurídica é mais recente e mais conturbada.

A quarta escala aqui descrita, de mais baixa intensidade, corresponde ao tratamento dispensado aos conflitos considerados não apenas pequenos, mas irrelevantes para o tratamento pelas instâncias formais do campo, correspondendo também aos litigantes que não contam. Não contam social e juridicamente, mas também não são contados pelos registros oficiais, porque a eles são reservados os rituais de administração de conflitos informais. Diferentemente do que acontece com os ritos judiciais informalizados, os rituais informais são procedimentos em que os agentes mais subalternos do campo dão soluções aos conflitos de forma extremamente rápida, sem respaldo em leis e direitos, fora do sistema legal, sem nenhuma forma de oficialização. 
As soluções ilegais implementadas por agentes estatais pertencem a esta escala de interação, embora nem todas as soluções aqui sejam ilegais. São formas de administração que incluem desde negociações realizadas diante das viaturas policiais a acordos firmados oralmente nos plantões das delegacias, até os diversos graus de administração violenta: de um tapa ou uma "geral" à tortura, troca de tiros e execução sumária. Essas formas de administração de conflitos foram descritas por Luciano Oliveira (2004) e por Kant de Lima (1995). O que caracteriza esta escala de interação é a sua completa informalidade e o bloqueio dos recursos legais e do acesso aos direitos. Nesta escala, são mais ativos os níveis hierárquicos mais baixos das profissões jurídicas: agentes policiais, conciliadores de juizados, mediadores leigos, delegados plantonistas, comissários de polícia. Esses rituais são administrados às pessoas que têm grande dificuldade de acesso aos direitos e ao sistema legal e que, além disso, ou em decorrência disso, têm pouquíssimo ou quase nenhum prestígio social: são os indesejáveis, os que não deveriam estar ali ou nem deveriam existir; aqueles cujas demandas, se tratadas pelas vias formais, congestionariam o plantão, os tribunais e explodiriam o sistema; ou ainda aqueles que merecem uma punição violenta ou até a morte; ou sequer merecem 15 minutos de atenção.

Contudo, mesmo na escala de baixíssima intensidade, as partes em conflito podem fazer uso da informalidade para a defesa de interesses e se considerarem satisfeitos com a solução obtida. O que eles não são capazes de defender aqui são direitos e garantias assegurados nas leis, pois o sistema teórico-prático que orienta a administração dos conflitos nesta escala está orientado por uma cultura jurídica não referenciada ao Estado de direito.

A tentativa de aproximação a essas quatro diferentes intensidades da administração estatal de conflitos produz um quadro em que há claramente desigualdades jurídicas que são reflexos, mas também produtoras, de desigualdade social. Um dos resultados importantes da dinâmica desse campo é a percepção popular, extremamente difundida, de que a quantidade de dinheiro que se tem afeta as chances de sucesso no acesso à justiça, de que "há uma justiça para ricos e outra para pobres", "rico não vai para a cadeia", o que sustenta uma desconfiança importante em relação às instituições policiais e judiciais e à justiça das leis.

Um dos juristas nacionais mais respeitados e citados, Ruy Barbosa, consagrou a teoria segunda a qual a igualdade é tratar desigualmente os desiguais, na medida em que se desigualam. Portanto, não chega a surpreender que a administração estatal de conflitos seja toda modulada em intensidades diferentes. Outra verdade frequentemente ouvida dos profissionais jurídicos é a de que "cada caso é um caso", expressando a ausência de pretensão de que regras universais possam ter validade no interior do campo. 


\section{Reformas judiciais e ativismo por direitos}

As duas últimas décadas, no entanto, foram marcadas por pressões sociais por reformas na polícia e no judiciário e por movimentos de ativismo por direitos coletivos. O campo de administração de conflitos não ficou inerte, vendo brotar inovações importantes, seja na implantação de juizados especiais, seja no incremento de delegacias especializadas de defesa da mulher, da criança, do idoso, delegacias de combate ao racismo e à discriminação, a instituição de varas agrárias para tramitar processos ligados à luta pela terra. O campo tornou-se mais politizado por lutas sociais, e o desempenho das instituições e dos agentes estatais esteve mais submetido à crítica interna, ao olhar da imprensa, e até à discussão dos cientistas sociais.

De um lado, é necessário constatar que o campo estatal de administração de conflitos vem sendo tensionado por lutas políticas em diversas esferas e atores politizados têm procurado introduzir inovações para lidar com a tensão. De outro, dada a fragmentação e a hierarquização do campo, muitas das políticas institucionais ou dos programas de melhoria de acesso à justiça terminam por constituir apenas mais um serviço e uma instância fragmentada, cujo prestígio em geral é muito pequeno. Os pesquisadores têm constatado que isto se passa com a justiça da infância e juventude (Silva, 1996), com as delegacias de defesa da mulher (Izumino, 2002; e estudos reunidos em Debert, Gregori \& Piscitelli, 2006), os juizados especiais (Azevedo, 2000) e os Centros de Integração da Cidadania (Sinhoretto, 2007) - todas elas inovações pensadas para reformar o sistema de justiça e a administração de conflitos ao ressignificar categorias e formas de tratamento ou reconstituir o estatuto de sujeitos de direitos; todas elas inovações que parecem ter ficado aprisionadas a lógicas de poder e a formas de administração de conflitos muito mais resistentes.

Do ponto de vista dessa antropologia política da administração de conflitos, os obstáculos às reformas das instituições judiciais tornam-se nítidos quando elas acabam por se parecer com um inventário de propostas parcialmente fracassadas por estarem aprisionadas a lógicas hegemônicas de administração de conflitos e a hierarquias estruturantes do campo, fazendo com que essas reformas atinjam apenas setores restritos, ou animem somente uma parte minoritária dos agentes, ou se moldem a estruturas de pensamento e a práticas preexistentes, perdendo sua força transformadora.

Há limites para uma intervenção ativista na medida em que temas universais são recebidos e ressignificados localmente, absorvidos pelo campo de acordo com suas lógicas e hierarquias internas. Dessa forma, quando um movimento social elege uma vítima emblemática, pode conseguir fazer com que aquele caso tenha um tratamento diferenciado, mas sem com isto conseguir mudar as categorias discriminatórias mais gerais que operam o campo. Contudo, em alguns casos, lutas sociais têm êxito ao deslocar um conjunto de conflitos e uma categoria de pessoas 
entre as escalas de intensidade. Com a criação dos juizados especiais, uma boa parte dos conflitos que antes não recebia um tratamento judicial passa a recebê-lo, ainda que por ritos informalizados, deslocando uma parte dos conflitos interpessoais da quarta para a terceira escala de intensidade, ou da completa informalidade para uma forma menos intensa de formalização. Isto, do ponto de vista de uma preocupação da extensão de direitos e garantias do Estado de direito a novos sujeitos, pode não significar muito, mas significa que um movimento social é capaz de provocar perturbações, deslocamentos e explorar fissuras no campo estatal de administração de conflitos.

Este é o caso do sucesso do movimento feminista em deslocar o tratamento de uma parte da violência doméstica de uma administração informalizada para uma escala mais formal de tratamento, porém ainda permeada por "falhas" e tratamentos desiguais. A Lei Maria Penha deslocou um conjunto dos conflitos violentos de gênero de uma escala menos intensa de direitos para uma mais intensa; ela, no entanto, não tem a potencialidade de reestruturar mais profundamente o campo a ponto de fazer com que todos os conflitos violentos de gênero recebam tratamento equitativo e regulado pela lógica dos direitos e da emancipação individual. ${ }^{12}$ Isto porque a quarta escala de intensidade, a da administração de conflitos fora do sistema legal, continua operativa e predominando nas franjas do campo.

Esta tem sido uma das ambiguidades da politização da justiça pelos movimentos sociais: de um lado, são produzidas transformações importantes, de outro, essas transformações são limitadas pela absorção das agendas reformistas por um campo habituado a fragmentações e a desigualdades de tratamento, podendo converter direitos em privilégios e revalidando hierarquias estruturantes do campo. Ao conduzirem lutas fragmentadas, os movimentos sociais acabam frequentemente aprisionados pelas hierarquias e pelas fragmentações do campo, sem conseguirem questionar globalmente a produção dessas hierarquias.

Por isso, o papel do ensino jurídico nessa reprodução tem sido cada vez mais questionado, ao mesmo tempo em que há uma aposta num potencial inovador que poderia brotar de ambientes universitários renovados. O ensino jurídico no Brasil teve grande expansão em escolas privadas que priorizam a massificação das atividades, o que significa que uma grande quantidade de profissionais está sendo produzida para ocupar posições subalternas num sistema hierarquizado. Por outro lado, uma formação em direito vai se popularizando e atingindo novas camadas sociais, o que pode também levar a uma perturbação das cômodas posições subalternizadas. Mas, como é impossível prever o futuro, retomamos a nossa agenda de pesquisa. 


\section{Notas}

1. Uma versão foi inicialmente apresentada em mesa-redonda da VIII Reunião de Antropologia do Mercosul, em Buenos Aires, em 2009, onde foi recebido com muitos comentários e sugestões estimulantes, que procurei incorporar.

2. Refiro-me aqui a um discurso político, presente em ativistas sociais e operadores jurídicos, até em agências multilaterais de cooperação, de apoio a projetos que fazem apelo à justiça informal ou justiça comunitária, que pode ou não incorporar estudos científicos, em que a noção de comunidade aparece como lugar de ausência de relações de opressão.

3. O modo como o "efeito Foucault" repercutiu sobre os estudos sobre crime e justiça nas ciências sociais brasileiras pode ser visto em Adorno (1994), Corrêa (1983), e na revisão bibliográfica organizada por Kant, Misse e Miranda (2000). Ver também a revisão em Sinhoretto (2007).

4. Uma primeira formalização do conceito de campo de gestão estatal de conflitos foi exposta em Sinhoretto (2007).

5. Como é o caso do delegado Protógenes Queiroz, da Polícia Federal, que foi afastado das investigações contra Daniel Dantas por acusações de abuso de poder nas investigações e produção de provas ilícitas. O delegado tornou-se uma figura popular dos noticiários e, recentemente, anunciou sua filiação a um partido político visando à candidatura a cargo eletivo nas próximas eleições. Outro exemplo é o do procurador da República, Luiz Francisco de Souza, que se tornou uma figura popular em 2003 ao investigar o secretário-geral da Presidência da República, Eduardo Jorge. A atuação do procurador nas investigações foi considerada abusiva a ponto de as regras de divulgação de informações para a imprensa terem sido alteradas. Em 2007, o Conselho Nacional do Ministério Público puniu o procurador.

6. Em contraste, há o caso de Eliza Samudio, que pediu medidas de proteção num processo judicial em que solicitava o reconhecimento de paternidade de seu filho com o famoso goleiro do Flamengo, Bruno. Entretanto, ela não conseguiu as medidas e está desaparecida há muitas semanas, provavelmente morta.

7. Foi-me sugerido que nessa escala de intensidade o uso do direito possa ser um instrumento de obtenção de privilégios por pessoas de alto prestígio social contra o direito de outros indivíduos cujas pretensões se oponham aos interesses dos primeiros. Esta é uma excelente pista para prosseguir na investigação.

8. Mais recentemente, a lei dos crimes hediondos foi considerada inconstitucional por vedar a progressão do regime de cumprimento de pena, protegida constitucionalmente.

9. Foi-me questionada a associação entre intensidade de exercícios dos direitos e formalidade judicial. É claro que a simples formalidade, sobretudo quando traduzida por excesso de burocratização na administração dos conflitos, não assegura o exercício dos direitos. Porém, a defesa de direitos individuais daqueles que ocupam as posições sociais mais subalternas só pode ser realizada com algum grau de formalização do ritual de administração de conflitos, no sentido de estabelecer na cena pública um equilíbrio de forças que não existe na vivência do conflito. Esta é uma questão que exige aprofundamento tanto teórico como de verificação empírica. 
10. A expressão “justice à deux vitesses” faz parte dos debates sobre reformas judiciais nos países francófonos, referindo-se à institucionalização de ritos e/ou instâncias de aceleração da tramitação de alguns tipos de casos com a flexibilização de algumas garantias processuais.

11. "Geral" é como os jovens costumam chamar as revistas policiais consideradas vexatórias, quando uma operação policial escolhe casualmente alguns jovens considerados "suspeitos" e os expõe publicamente de várias formas, revistando o corpo, as bagagens, fazendo-os ficar enfileirados contra um muro, com as mãos atrás da cabeça.

12. Dados preliminares da avaliação do impacto de implantação da Lei Maria da Penha apontam inclusive para uma redução das possibilidades de acesso à justiça: no Rio Grande do Sul, por exemplo, o deslocamento dos casos de violência contra a mulher dos juizados para as varas criminais reduziu o número de juízes e a estrutura de processamento disponíveis para a administração desses conflitos. Aquilo que teoricamente poderia ampliar as possibilidades de exercício dos direitos individuais é capaz de, na prática, por causa do poder desmobilizador das ações fragmentárias, concretizar um aumento das barreiras de acesso. Estes paradoxos é que precisam ser explorados para uma melhor compreensão do campo estatal de administração de conflitos fragmentado e plural. 


\section{Referências bibliográficas}

ADORNO, Sérgio. 1994. "Crime, justiça penal e desigualdade jurídica: as mortes que se contam no tribunal do júri”. Revista USP, São Paulo, Universidade de São Paulo, n. 21:132-151, mar.-maio.

AZEVEDO, Rodrigo Ghiringhelli de. 2000. Informalização da justiça e controle social. Estudo sociológico da implantação dos Juizados Especiais Criminais em Porto Alegre. São Paulo: IBCCrim.

BONELLI, Maria da Glória. 2002. Profissionalismo e política no mundo do direito. As relações dos advogados, desembargadores, procuradores de justiça e delegados de polícia com o Estado. São Carlos: Edufscar/Sumaré.

BOURDIEU, Pierre. 2007. O poder simbólico. 10. ed. Rio de Janeiro: Bertrand Brasil.

CORRÊA, Mariza. 1983. Morte em família. Representações jurídicas de papéis sexuais. Rio de Janeiro: Graal.

DAMATTA, Roberto. 1979. Carnavais, malandros e heróis. Para uma sociologia do dilema brasileiro. Rio de Janeiro: Zahar.

DEBERT, Guita; Gregori, M. Filomena \& Piscitelli, Adriana. 2006. Gênero e Distribuição da Justiça: as Delegacias de Defesa da Mulher e a construção das diferenças. São Paulo: Unicamp/ Pagu - Núcleo de Estudos de Gênero [Coleção Encontros].

DUMONT, Louis. 1966. Homo hierarchicus. Le système des castes et ses implications. Paris: Galimard.

IZUMINO, Wânia Pasinato. 2002. "Delegacias de Defesa da Mulher e Juizados Especiais Criminais: contribuições para a consolidação de uma cidadania de gênero". Revista Brasileira de Ciências Criminais, ano 10, n. 40:282-295, out.-dez.

KANT DE LIMA, Roberto. 1995. A polícia da cidade do Rio de Janeiro: seus dilemas e paradoxos. Rio de Janeiro: Forense.

2004. "Direitos civis e direitos humanos: uma tradição judiciária pré-republicana?”. São Paulo em Perspectiva, 18 (1):49-59.

. 1997. Roberto. "Polícia e exclusão na cultura judiciária”. Tempo Social, Rev. Sociol., USP, São Paulo, v. 9, n. 1:169-183, maio.

. Misse, Michel \& Miranda, Ana Paula. 2000. "Violência, criminalidade, segurança pública e justiça criminal no Brasil: uma bibliografia”. BIB - Rev. Bras. de Informação Bibliográfica em Ciências Sociais, Rio de Janeiro, ANPOCS/Relume Dumará, n. 50:45-123, $2^{\circ}$ sem.

MILLER, Peter; Gordon, Colin \& Burchell, Graham. 1991. Foucault Effect. Chicago: University Press. 
OLIVEIRA, Luciano. 2004. Sua Excelência o Comissário e outros ensaios de Sociologia Jurídica. Rio de Janeiro: Letra Legal.

SILVA, Cátia Aida. 1996. A disputa pela jurisprudência na área da infância: promotores, juízes e adolescentes infratores. Paper apresentado à XX Reunião Anual da ANPOCS, Caxambu-MG, 22 a 26 de outubro.

- 2001. Justiça em jogo. Novas facetas da atuação dos promotores de justiça. São Paulo: Edusp.

SINHORETTO, Jacqueline. 2007. Ir aonde o povo está: etnografia de uma reforma da justiça. Tese de Doutorado, Universidade de São Paulo, Departamento de Sociologia. Disponível em www.teses.usp.br. 


\section{Resumo}

O artigo propõe uma interpretação do funcionamento do campo estatal de administração de conflitos da perspectiva das disputas entre as corporações, os conhecimentos e as instituições que dele participam. A reflexão sobre o caso brasileiro propõe a coexistência de pelo menos quatro lógicas de administração de conflitos ou quatro intensidades de interação, às quais correspondem hierarquias de rituais de administrações de conflitos, pessoas, tipos de conflito e lugares. Por essa análise, os procedimentos judiciais ordinários, os juizados informalizados, as técnicas extrajudiciais e os procedimentos policiais formais e informais e, inclusive, os procedimentos ilegais coexistem e disputam a administração dos conflitos, num campo estatal que produz constantemente a desigualdade de tratamento.

\section{Palavras-chave}

Antropologia jurídica, antropologia política, justiça, administração de conflitos, campo jurídico.

\begin{abstract}
The article propose an interpretation of the functioning of the State conflict settlement field from the perspective of disputes among corporations, knowledge and institutions that take part of it. A reflection on the Brazilian case proposes the coexistence of at least four conflict settlement logics or four interaction intensities to which correspond hierarchies of rituals, persons, types of conflict and places. For this analysis, ordinary court proceedings, informalized courts, extra-judicial techniques, formal and informal police procedures, including illegal ones, coexist and dispute the conflict settlement, in a State field that produces unequal treatment.
\end{abstract}

\section{Key words}

Anthropology of Law, Anthropology of Power, justice, conflict settlement, Brazil. 